Lectures and Conferences on Mathematical Statistics Delivered by J. Neyman. Revised and Supplemented by the Author with the editorial assistance of W. Edwards Deming. Pp. ix +160 . (Washington: Graduate School of the U.S. Department of Agriculture, 1938.) 1.25 dollars.

JN April 1937, Dr. J. Neyman, of the Department 1 of Statisties, University College, London, delivered three lectures and was the leading speaker at six conferences, all held at the Graduate School of the United States Department of Agriculture, Washington. The lectures were on the theory of probability, on probability and experimentation, and on the testing of statistical hypotheses. The conferences dealt with randomized and systematic arrangements of field experiments, plant breeding, sampling in social problems, analysis of time series, statistical estimation, and confidence intervals.

The conferences were particularly valuable, as those present, many of whom were themselves eminent experts, put searching questions concerning difficult points. In the verbatim reports of these questions and Dr. Neyman's answers, the student will find a discussion of the relative values of alternative methods and of the relationship between alternative theories, which is almost unobtainable elsewhere. The theory of statistical inference seems to be still in a very unsettled state, and the procedure recommended by one authority for conducting, for example, an agricultural experiment, is disapproved of by another authority. Perhaps the differences are not always as serious as they at first appear. Thus Dr. Neyman's theory of confidence intervals cannot, it is insisted, be reconciled with Prof. R. A. Fisher's theory of fiducial probability, but so far the numerical results obtained have been the same, and it is possible that this will always be the case.

H. T. H. P.

\section{Diesel Engine Design}

By H. F. P. Purday: Fourth edition. Pp. xix + $520+4$ plates. (London: Constable and Co., Ltd., 1937.) 24s. net.

T HIS is the fourth edition of a work which first appeared in 1920, and that the fourth edition is called for so soon indicates the value of this book.

A comparison of the new edition with the last gives a very good idea of the progress made in Diesel engine design since 1928, as the author now finds it necessary to include new chapters dealing respectively with supercharging, torsional vibration, structural vibration, lubrication and noise : all these subjects have come into the foreground in that interval.

The title of the book is accurate, since the contents deal more with the art of design than with the sciences of the subject, although this is not to say that the latter are not taken fully into account; each chapter concludes with references to original papers which a reader may consult for a fuller treatment. The reviewer concludes by repeating a remark made in reference to the third edition: "Altogether any criticisms of the book relate only to details, and the author is to be congratulated on having written one of the best books of its kind".

\section{Strahlen um Uns}

Von Heinz Tschelnitz. Pp. ii +80 . (Brünn, Prag, Leipzig, Wien : Rudolf M. Rohrer, 1938.) 20 Kč.

\section{$\mathrm{T}$} HIS little book is a survey of the chief questions of what is termed radiobiology. Though it contains a certain amount of controversial matter and not a few speculations, it will interest both physicists and biologists by directing the attention of each to recent researches of the other connected with radioactive and electromagnetic radiations. Evidence is adduced that all living creatures are continually subjected to the influence of such radiations. For example, animals breathe ordinary air which contains radium emanation; their food and drinking water contain a small but definite amount of radioactive salts, and cosmic rays play on them from above. The organs of animals contain minute quantities of radioactive substances.

The author supports the view of Stoklasa that a certain concentration of radioactive elements is natural and proper in any healthy living organism, but that any concentration in excess of this has a pathological effect. He thinks that the relations of radioactivity to life are only just beginning to be understood, and he sees in the further study of the biological action of radiations the likeliest direction of progress in the understanding of life itself. Though the reader may not agree with the author's views concerning the mitogenetic rays of Gurwitsch (cf. NATURE, 119, 556; 1927), the dependence of water divining and cancer on the emission of rays by the earth, and other topics, he will find the speculations entertaining, if not always convincing.

\section{A Course of Pure Mathematics}

By Prof. G. H. Hardy. Seventh edition. Pp. xii +498 , (Cambridge : At the University Press, 1938.) 12s. 6d. net.

7 HE seventh edition of this famous text-book, first published in 1908, has now appeared. It has been revised and reset. The Cambridge Press mathematical printing is better than ever, the spacing and general lay-out of the formulæ being excellent. A large number of new examples from the Mathematical Tripos have been included. The sections on the elementary properties of differential coefficients have been revised, following the treatment in de la Vallée-Poussin's "Cours d'Analyse". Apart from this, the general scheme of the book is unchanged. The author says that the book was written at a time when analysis was neglected in Cambridge, and that if he were to rewrite it now it would be less like "a missionary talking to cannibals" and more like the usual "Traité d'Analyse". No one will regret that he has not made the change. If we all live now on a decent mathematical diet it is due in no small part to the influence of this book. They say that analysis has passed the peak of its popularity; but studies of this kind can never be out of date. We believe that our successors will continue to derive the same inspiration from this book that it has given to us in the past thirty years.
E. C. T. 